\title{
Aerodynamic and Performance Characteristics of a Passive Leading Edge Kruger Flap at Low Reynolds Numbers.
}

\author{
V.M. Moraris， N.J.Lawson， K.P.Garry \\ School of Engineering, Cranfield University, Beds. MK430AL UK \\ Tel no: +44 (0) 1234 750111, Fax: +44(0) 1234758245
}

\begin{abstract}
An experimental and numerical study was performed on a Clark Y aerofoil with a $10 \%$ chord leading edge Kruger flap to examine its aerodynamic performance at Reynolds numbers of $0.6 \times 10^{6}, 1 \times 10^{6}$, and $1.6 \times 10^{6}$, to help to identify the forces and moments acting on a basic configuration. A detailed comparison of the numerical and experimental data is presented in this paper. The leading edge flap was effective at high angles of attack with an increase in $\mathrm{C}_{\mathrm{L}}$ of up to $18 \%$ over a conventional no flap configuration and delayed separation by up to $3^{\circ}$. The moments around the Kruger flap rotation point were calculated from the numerical analysis as an initial stage in the design of a UAV passive flap system and they are also presented in the paper.
\end{abstract}

\section{Nomenclature}

$\begin{array}{ll}A & =\text { reference area }\left(\mathrm{m}^{2}\right) \\ \alpha & =\text { angle of attack }(\text { degrees }) \\ C_{p} & =\text { pressure coefficient } \\ C_{L} & =\text { Lift coefficient }(\mathrm{L} / \mathrm{qA}) \\ C_{D} & =\text { Drag coefficient }(\mathrm{D} / \mathrm{qA}) \\ \mathrm{c} & =\text { Aerofoil chord }(\mathrm{m}) \\ D & =\text { Drag force }(\mathrm{N}) \\ L & =\text { Lift force }(\mathrm{N}) \\ \delta & =\text { flap angle }(\text { degrees }) \\ \mathrm{q} & =\text { freestream dynamic pressure }(\mathrm{Pa}) \\ \mathrm{M} & =\text { Moment of flap around rotational point }(\mathrm{Nm})\end{array}$

\section{Introduction}

Recent publications examining the flight of eagles have shown that leading edge feather deflections occur on the lower surface of the wings in free flight, to create a leading edge flap ${ }^{(1)}$ analogous to a Kruger flap system. Such passive high lift devices may be adaptable to the lifting surfaces of unmanned air vehicles (UAVs). This paper presents an experimental and numerical approach to obtain the forces and moments acting on a Kruger flap configuration in the low Reynolds number region at which UAVs operate, where the aerodynamic characteristics of Kruger flaps are not well documented. This work is aimed at an application of a passive leading edge Kruger device which will self-deploy as required, in the take-off and landing stage of the UAV flight.

Experiments performed by Bakhtian and Babinsky ${ }^{(2)}$, as well as $\operatorname{Kruger}^{(3-4)}$ and Fullmer ${ }^{(5,6)}$, indicated that significant lift coefficient gains can be obtained from the implementation of a Kruger high lift device at Reynolds numbers Re, based on chord length, of $4 \times 10^{3}$ to $1.4 \times 10^{4}$ and $6 \times 10^{6}$. Fulmer's experiments showed a $30 \%$ increase in maximum lift coefficient when a Kruger flap was deployed from the lower surface of the aerofoil at $\operatorname{Re}=6 \times 10^{6}$. Numerical results indicate that, adjacent to the point of maximum flap curvature, an accelerated region generates a significant fall in $\mathrm{C}_{\mathrm{P}}$ followed by a substantial adverse pressure gradient, resulting in a region of separated flow. The extent of the separation is related to the degree of curvature in the leading edge region as this leading edge geometry 
approximates an "ever-opening spiral" (see Figure 1). The less severe separation thus removes the need for a slot or a boundary layer control device to reattach the flow at a sharp corner or knee ${ }^{(7)}$. This simple arrangement may also lend itself to application in a self deploying high lift UAV device, such as is observed in the flight of an eagle.

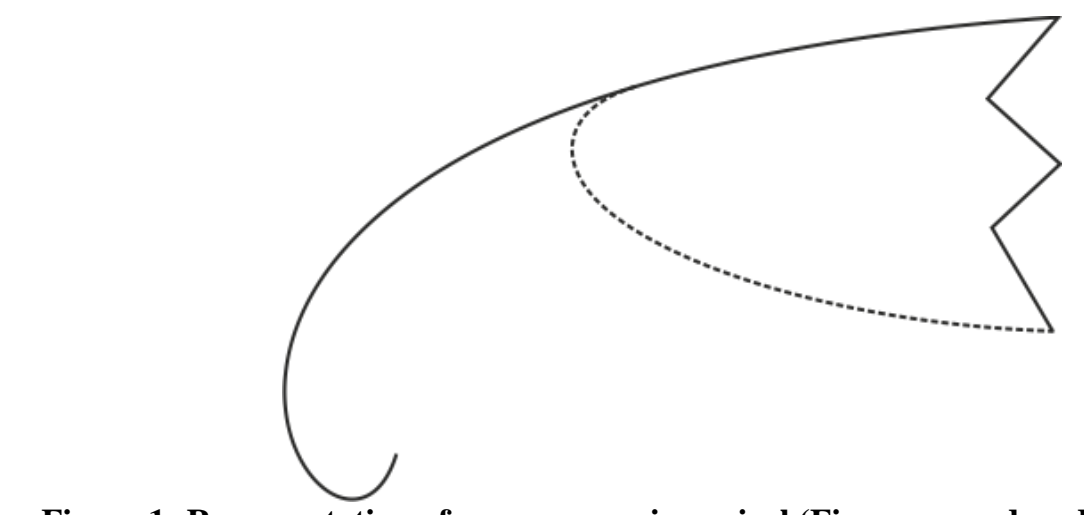

Figure 1: Representation of an ever-opening spiral (Figure reproduced from ref 7)

\section{Basic Kruger System}

The following study aims to identify the forces and moments acting on a basic Kruger flap configuration, as outlined in Figure 2 below, and further to establish the deployment load (in the form of flap hinge moment) for either a shape alloy or passive actuator design. A Clark Y aerofoil with a $0.61 \mathrm{~m}$ chord has been used in all the experimental studies and CFD simulations. The leading edge flap of $61 \mathrm{~mm}$, corresponding to $10 \%$ chord, was constructed in such a way as to match the geometry of the lower surface of the aerofoil (see Figure 2).

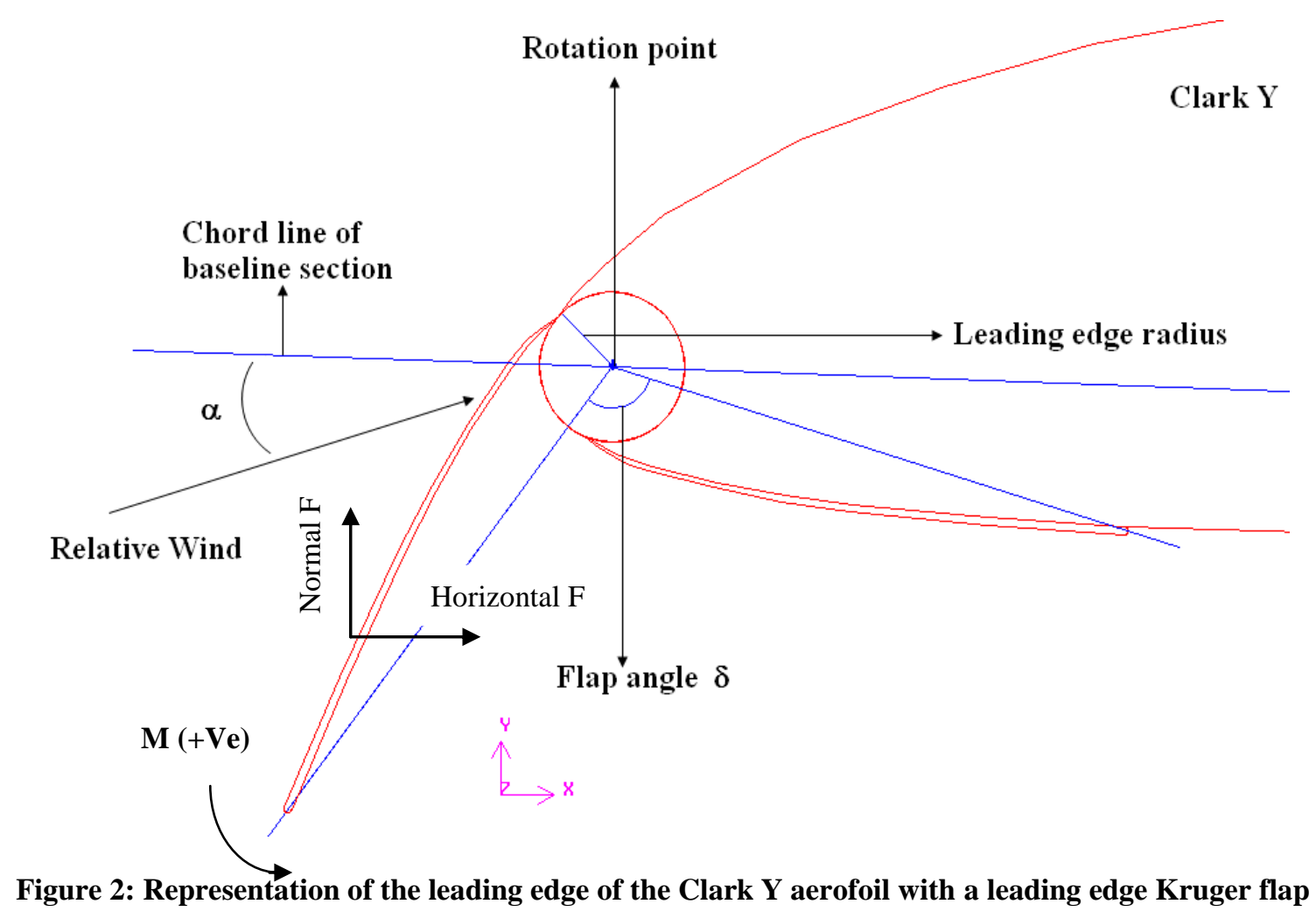




\section{Experimental Measurements}

An experimental investigation was carried out in the $2.4 \mathrm{~m} \times 1.8 \mathrm{~m}$ general purpose wind tunnel at Cranfield University. This facility has a closed return layout with a closed rectangular working section, providing test section flow velocities in the range $5-55 \mathrm{~m} / \mathrm{sec}$, with a freestream longitudinal turbulence intensity of $0.9 \%$ at $45 \mathrm{~m} / \mathrm{sec}$. Two-dimensional (2D) aerofoil testing was carried out using a rectangular platform wing section with an aspect ratio $(\mathrm{AR})=2$, mounted horizontally at mid test section height, between circular end-plates (see Figure 3). The end-plates serve to ensure nominally $2 \mathrm{D}$ flow conditions on the wing and provide fairings for the struts connecting the section model to the overhead six component weighbeam mechanical balance. Incidence adjustment was by means of a tail wire and conventional pitch-strut assembly. Measurements of aerodynamic force, moment and pressure were made over the same range of aerofoil incidence and Reynolds number as used in the CFD study. The body pressure measurements were obtained using a combination of a Furness Controls FC0318 differential pressure system and a PX139 0.3psi Series pressure transducer. These devices were connected sequentially to the surface pressure tapings using equal length pressure tubes. Each measurement was sampled over a 10 second time period at a sample rate of $300 \mathrm{~Hz}$. Investigation of the damping effects of the pressure tubes connecting the tapings revealed a 5 second settling time was sufficient to overcome any damping errors. Tunnel velocity was calculated using the pressure output from a static ring set connected to the FC0318 pressure system.

The $0.61 \mathrm{~m}$ chord aerofoil was fitted with a $10 \%$ chord composite Kruger flap element which was manually adjusted by means of end-plate mounted setting screws. The flap was initially secured to the leading edge of the main aerofoil. During these initial tests, however, the spanwise rigidity of the flap was not sufficient and therefore a series of formers at five spanwise locations were added to maintain the required flap cove geometry at each flap deflection (see Figure 3). The runs where carried out at operating Reynolds numbers Re based on chord in the range of $\operatorname{Re}=0.6 \times 10^{6}$ to $\operatorname{Re}=1.6 \times 10^{6}$, where small and medium size UAVs (Tactical UAVs) operate ${ }^{(8)}$. However, initial surface flow visualisation of the aerofoil, using fluorescent pigment suspended in paraffin, indicated turbulent transition near the leading edge of the aerofoil due to the surface condition of the leading edge, which contained the flap mounting points. A similar leading edge transition location was also found with the flap fitted, due to the joint between the flap and the leading edge.

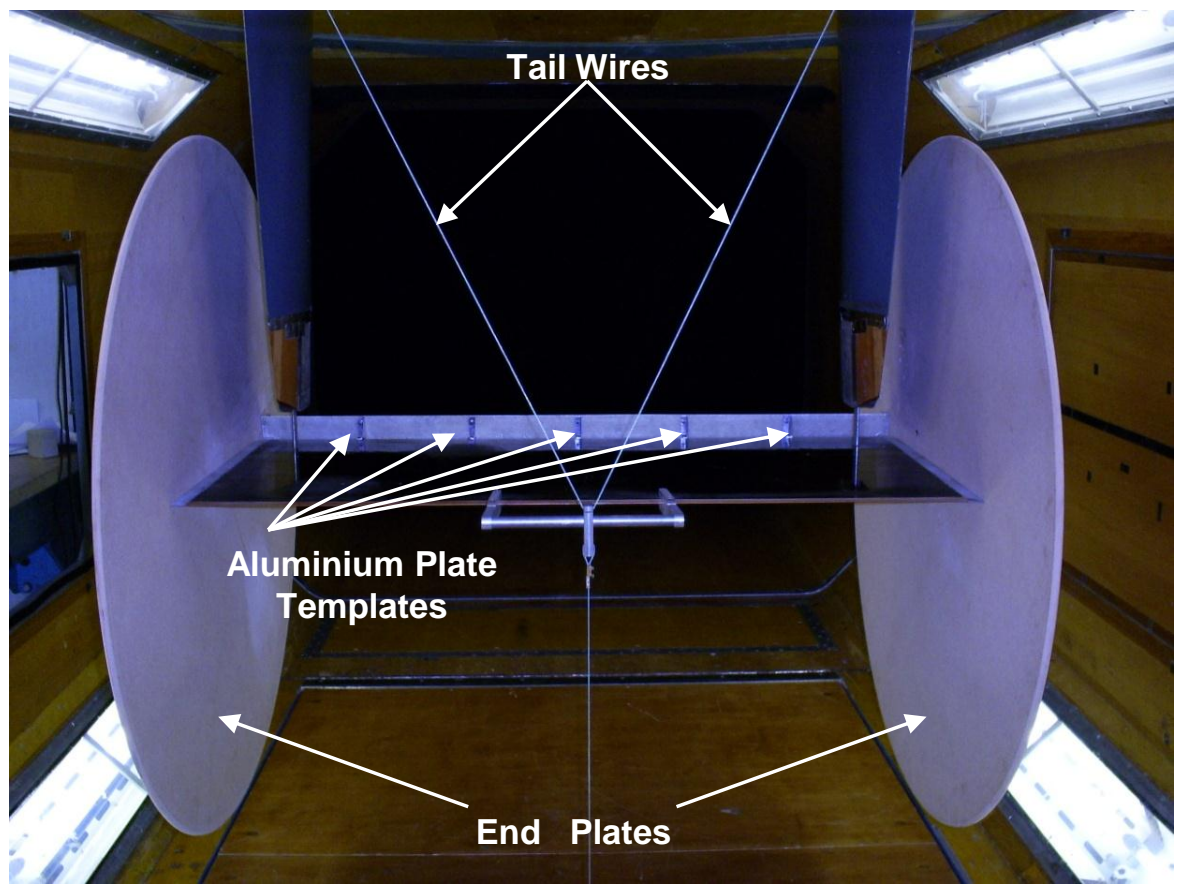

Figure 3: Rear view of the wing and flap experimental apparatus used (wing in inverted position)

The accuracy of the lift and drag measurements through a static load calibration was estimated to be $\pm 1.02 \mathrm{~N}$ and $\pm 0.88 \mathrm{~N}$ respectively. This corresponded to full scale errors of $\pm 0.068 \%$ and $\pm 3.1 \%$ in lift and drag which translated to $\pm 0.26 \%$ and $\pm 3.2 \%$ errors in estimates of $C_{L}$ and $C_{D}$ respectively. Pressure coefficient, $C_{p}$, measurements were 
expected to be better than $\pm 1.44 \%$ based on a $\pm 0.25 \%$ and $\pm 1 \%$ full scale error in pressure from the FC0318 and PX139 pressure systems respectively.

\section{Baseline Numerical Model}

To establish detailed aerodynamic force and moment characteristics of the Kruger flap for subsequent design of the self-deploying flap, a two-dimensional (2D) CFD model was developed. The initial baseline numerical model used the configuration outlined in Figure 2, with the Kruger flap angle set to $0^{\circ}$. These baseline conditions were representative of standard Clark Y aerofoil. The baseline CFD model validation was possible through previous experimental data and wind tunnel data taken for this work. A dimensional analysis of the system also allowed CFD conditions and a wind tunnel test matrix to be defined.

The commercial CFD code Fluent was used to solve the flow field around the aerofoil from the Reynolds Average Navier-Stokes (RANS) equations. A domain with dimensions of 20x20 chords with the aerofoil in the middle was used to accommodate the flow. The free stream turbulence intensity and hydraulic diameter used for the numerical analysis were set at $0.9 \%$ and $1.829(\mathrm{~m})$ respectively, to represent the turbulence intensity and height of the wind tunnel.

The mesh density and the selection of a turbulence model are critical to the accuracy of the CFD solution. Thus a comprehensive review of literature indicated a suitable turbulence model for the Kruger flap system to be the K- $\omega$ SST model ${ }^{(-16)}$. As the initial wind tunnel test indicated turbulent transition to occur at the leading edge region of the aerofoil, a turbulent model was used throughout the mesh for all subsequent modelling with no laminar transition. A hybrid mesh was generated using Gambit, with structured quad cells at the aerofoil and near wall flap regions and pave triangular cells in the rest of the domain.

Initially a grid was generated to examine the flow around a clean Clark-Y aerofoil (baseline model) and a mesh density investigation was performed to verify grid-independence of the solution. To resolve the turbulent boundary layer region, the boundary layer mesh was generated using a geometric stretching ratio (SR) not exceeding 1.2, which according to the analysis performed by Spalart ${ }^{(17)}$ provides the optimal grid distribution when the grid is clustered with a corresponding value of $y^{+} \leq 1$ for each Reynolds number. Enhanced Wall Treatment was used to resolve the near wall viscous sublayer region using the two-layer zonal model. Typical baseline hybrid meshes are shown in Figure 4, Figure 5 and Figure 6.

The RANS equations were solved using the finite volume method. Second order upwind discretisation in space was used and the resulting equations solved using the SIMPLE algorithm until convergence criteria were satisfied. The convergence was based on the behaviour of the discrete solution with the error $(\mathrm{E})$ of the solution corresponding to the difference between the discrete solution $f(\Delta)$ and the exact continuum solution $f^{\text {exact }}$ of the model equations ${ }^{(18)}$. Discretisation errors (E) arise due to the difference between the exact continuum solution $f^{\text {exact }}$ of the model equations and the discrete solution $f(\Delta)^{(18)}$. If the flow solution is represented through a Taylor series, the exact continuum solution occurs when the truncation error is effectively zero, which is a function of the grid size. Convergence was monitored through plots of the residuals in lift and drag coefficient versus iteration number and the solution was assumed to be converged when the residuals dropped to at least four orders of magnitude smaller than $\mathrm{C}_{\mathrm{L}}$ and $\mathrm{C}_{\mathrm{D}}$ with zero gradient.

Lift and drag forces were obtained using near-field integration of the pressure and viscous forces around the aerofoil with a function provided by Fluent. From these forces, the drag and lift coefficients $C_{D}$ and $C_{L}$ were calculated for different angles of attack.

For mesh verification, the model was initially run with three meshes, doubling the number of grid points each time $^{(18,19)}$ (see Table 1), for Reynolds numbers of $\mathrm{Re}=0.6 \times 10^{6}, \mathrm{Re}=1.0 \times 10^{6}$ and $\mathrm{Re}=1.6 \times 10^{6}$. From these solutions, the values of $\mathrm{C}_{\mathrm{L}}$ were compared and found to have a variation of less than $0.5 \%$ when comparing Mesh 2 and Mesh 3 for all Reynolds numbers. For validation, the $C_{L}$ and $C_{D}$ results from Mesh 3 where then compared with data obtained from the literature ${ }^{(20)}$, flat plate theory and data obtained from wind tunnel tests performed as part of this project. In this case, Mesh $3 \mathrm{C}_{\mathrm{L}}$ results matched to within 5\% and therefore Mesh 3 was used as the initial grid for modification for the more complex Kruger flap configurations. 


\begin{tabular}{|c|c|c|c|}
\hline & Mesh 1 & Mesh 2 & Mesh 3 \\
\hline Total no. Cells & 66000 & 270000 & 880000 \\
\hline
\end{tabular}

Table 1: Grid size for each case examined

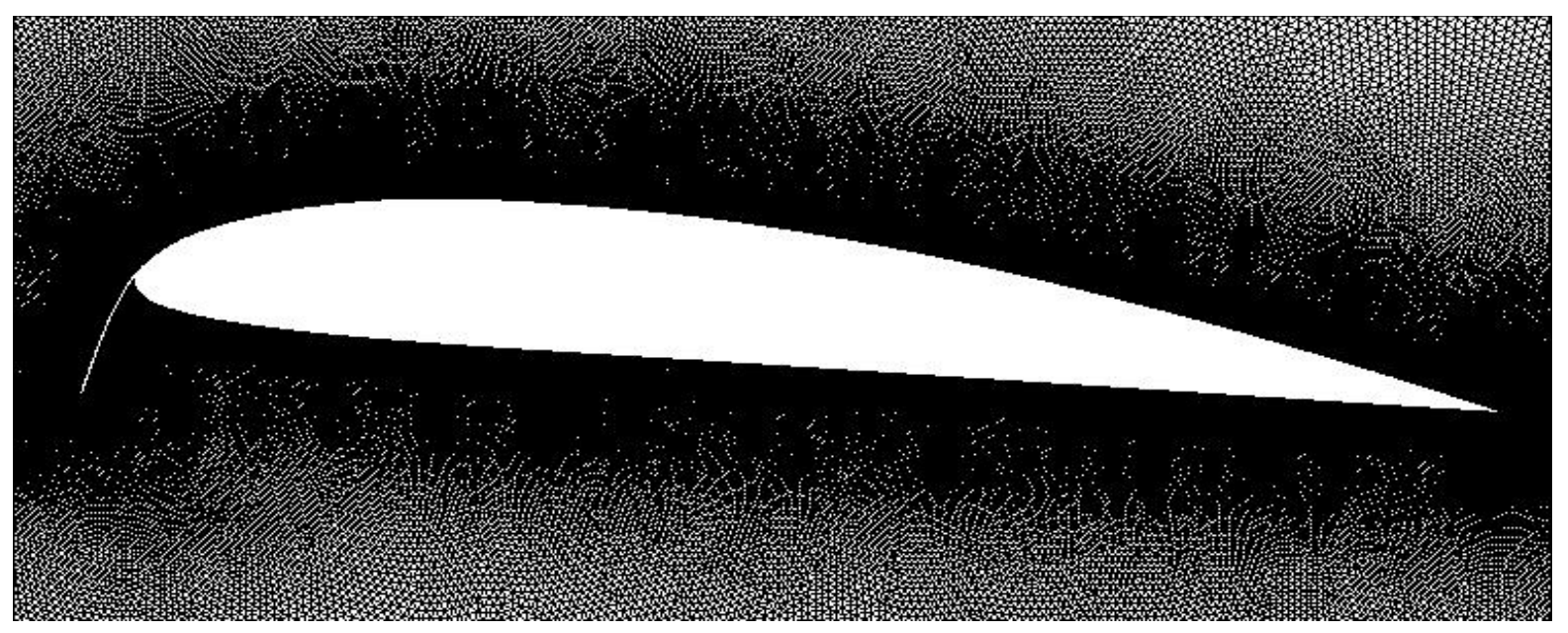

Figure 4: Hybrid grid used for the CFD analysis

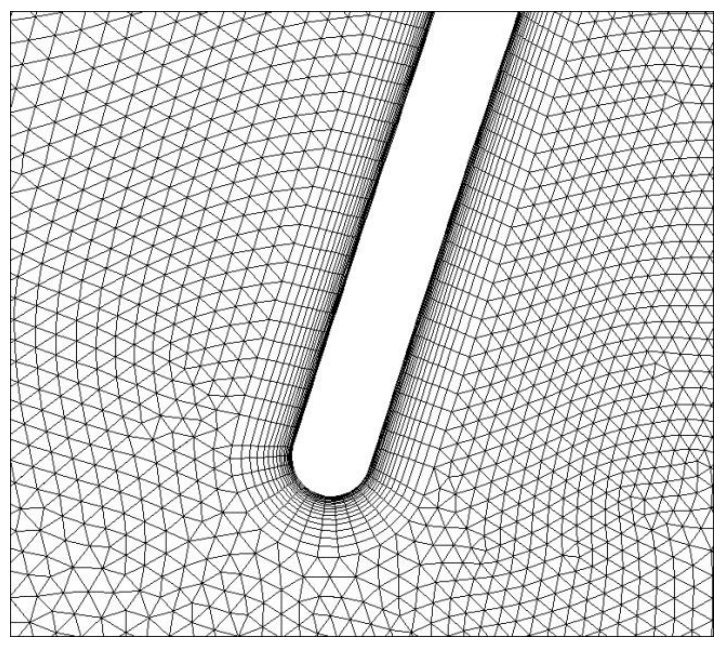

Figure 5: Magnification of the grid on the leading edge. 


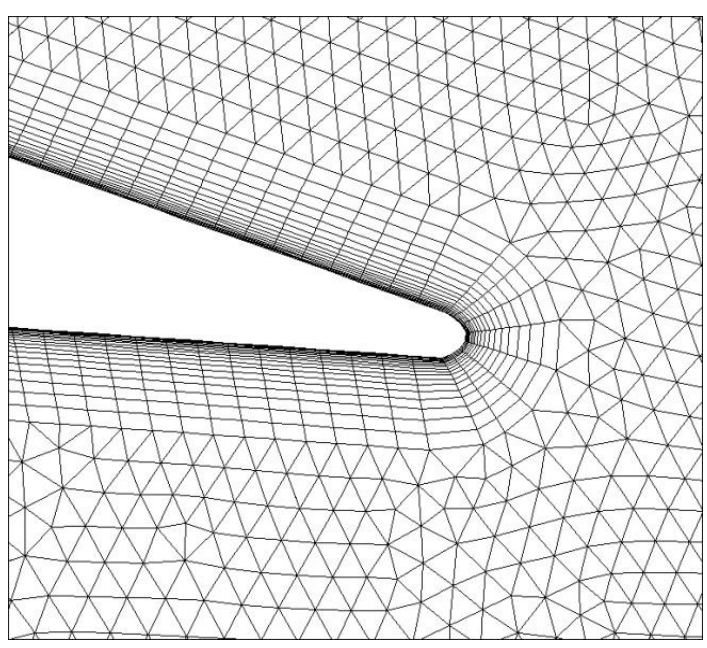

Figure 6: Magnification of the grid on the trailing edge.

Figure 7, Figure 8 and Figure 9 show the baseline $C_{L}-\alpha$ and $C_{D}-\alpha$ data where it can be seen that the $C_{L}$ for all cases is predicted to within $5 \%$ of full scale experimental data ${ }^{(20)}$. The $C_{D}$ values are in good agreement with the experimental values at low angles of attack for all three cases. On average the k- $\omega$ SST model displays $21 \%$ lower $\mathrm{C}_{\mathrm{D}}$ values than the wind tunnel experimental tests. However, although prediction of lift and drag with k- $\omega$ SST model was improved, this under estimate of drag is still significant. At this stage, based on results in similar CFD applications, it is thought a major element of this discrepancy can be attributed to the turbulence model ${ }^{(21)}$.

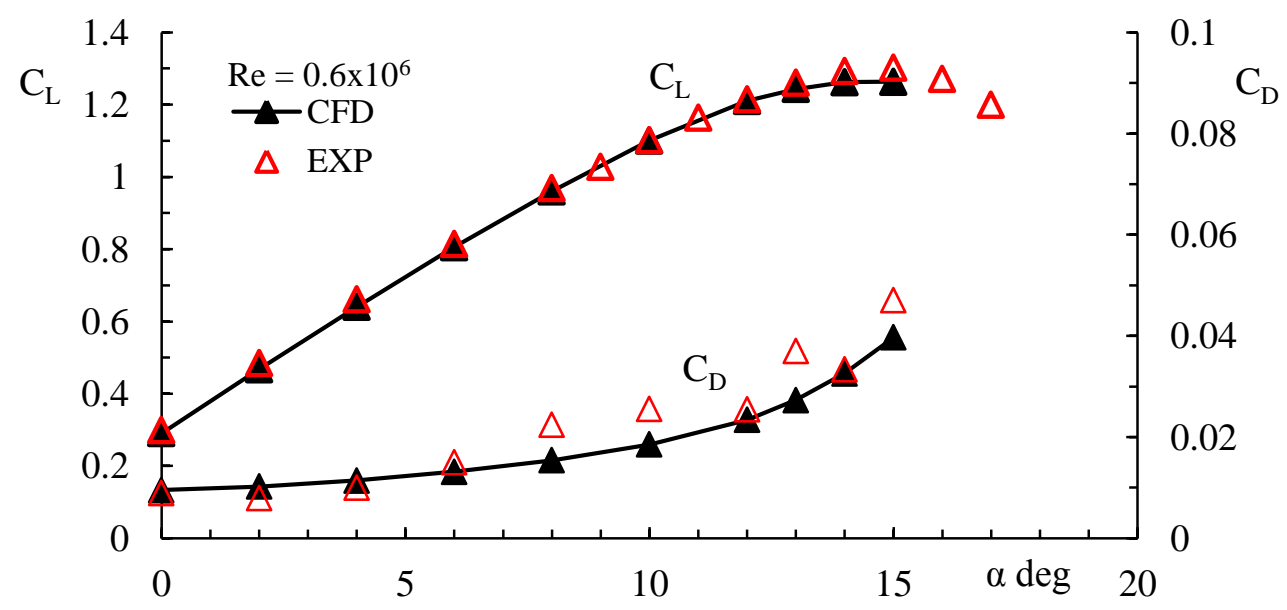

Figure 7: $C_{L}$ and $C_{D}$ plots over a range of angles of attack of the numerical and experimental results for a baseline Clark $\mathrm{Y}$ at $\mathrm{Re}=0.6 \times 10^{6}$. 


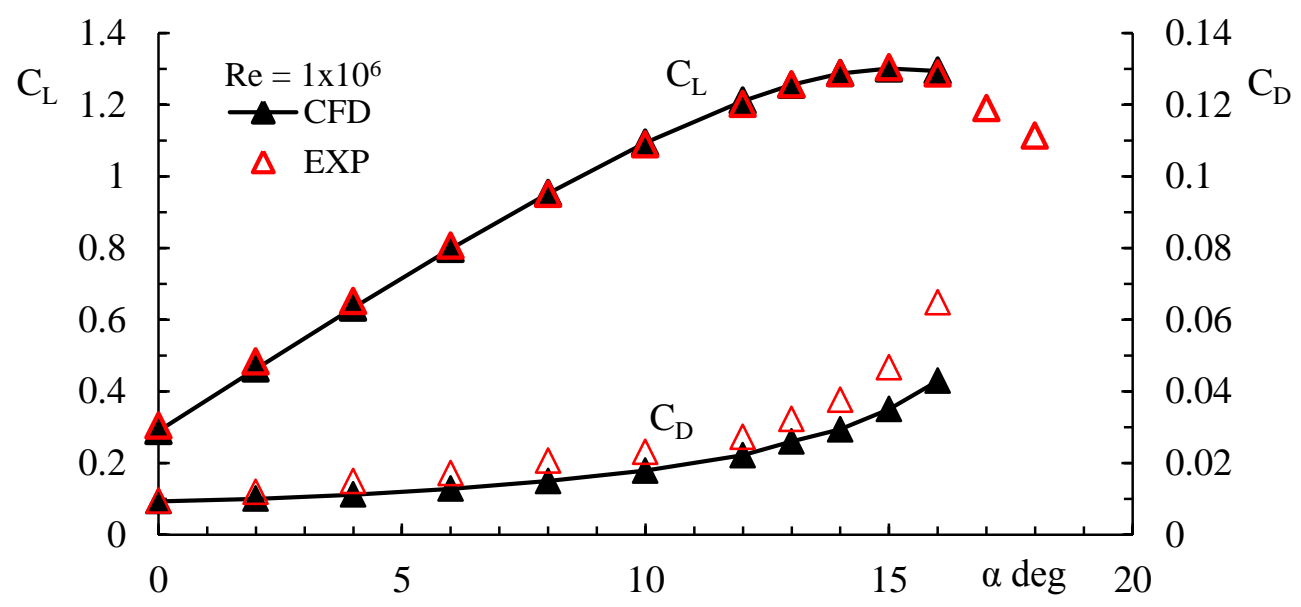

Figure 8: $C_{L}$ and $C_{D}$ plots over a range of angles of attack of the numerical and experimental results for a

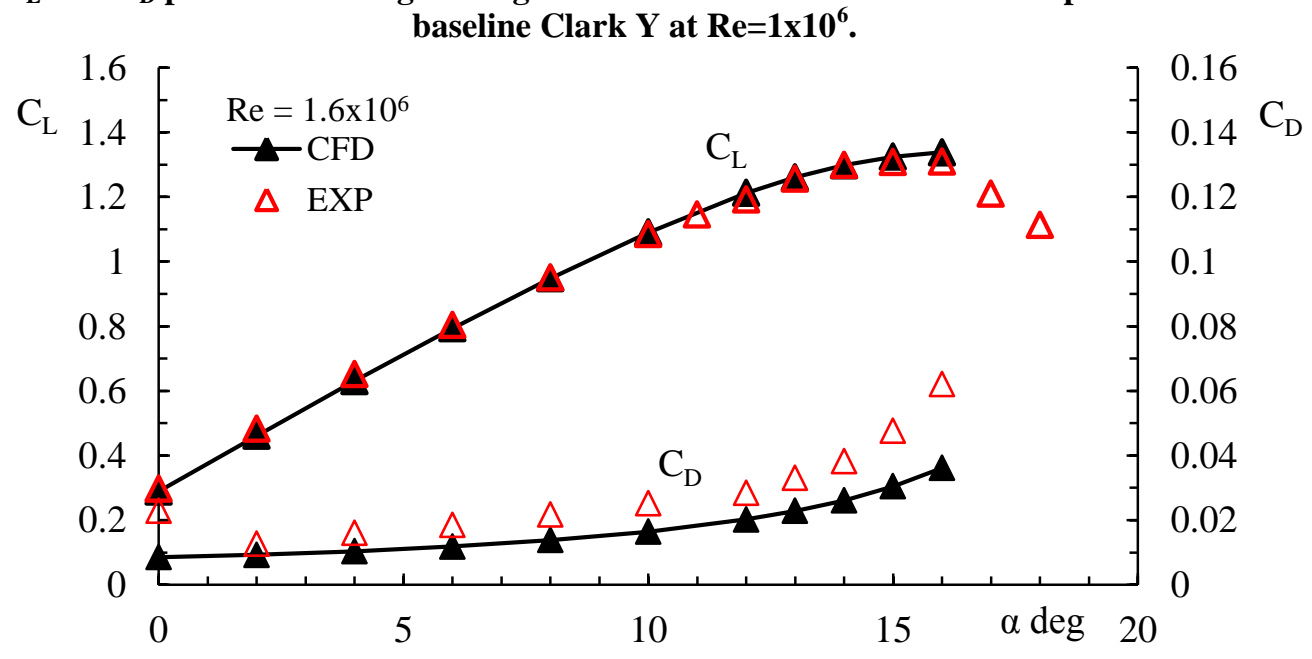

Figure 9: $C_{L}$ and $C_{D}$ plots over a range of angles of attack of the numerical and experimental results for a baseline Clark $\mathrm{Y}$ at $\mathrm{Re}=1.6 \times 10^{6}$.

\section{Leading Edge Flap Numerical Modelling}

Following the baseline CFD studies, a further set of 2D numerical studies were completed for a range of angles of attack $\alpha$ from $0^{\circ}$ to $18^{\circ}$ and a range of Kruger flap angles $\delta$ varying from $70^{\circ}$ to $110^{\circ}$ for each angle of attack. The domain and grid density used for this study was similar to the baseline aerofoil case. The Clark Y aerofoil and Kruger flap configuration shown in Figure 2 was used throughout this part of the investigation at Reynolds numbers $(\mathrm{Re})$ of $0.6 \times 10^{6}, 1 \times 10^{6}, 1.6 \times 10^{6}$. The $\mathrm{C}_{\mathrm{L}}$ plots reveal an increase in the maximum lift coefficient of between $15 \%$ $18 \%$ at a stall angle of $\alpha=16^{\circ}$ and flap deflection angle of $\delta=110^{\circ}$ for all three Re numbers. Similarly, at $\delta=100^{\circ}$ the increase in the maximum lift is between $11 \%$ - 12\% (see Figures $10-12$ ). No significant increase in $\mathrm{C}_{\mathrm{L}}$ for $\delta$ $=70^{\circ}$ was observed. The results obtained from the numerical analysis of the aerofoil and flap configuration were compared with equivalent experimental results obtained from the Cranfield wind tunnel, as well as the baseline results for a clean Clark $\mathrm{Y}$ and these are also shown in Figure 10. In this case, the experimental and numerical values of $\mathrm{C}_{\mathrm{L}}$ are within $5 \%$ of each other. 


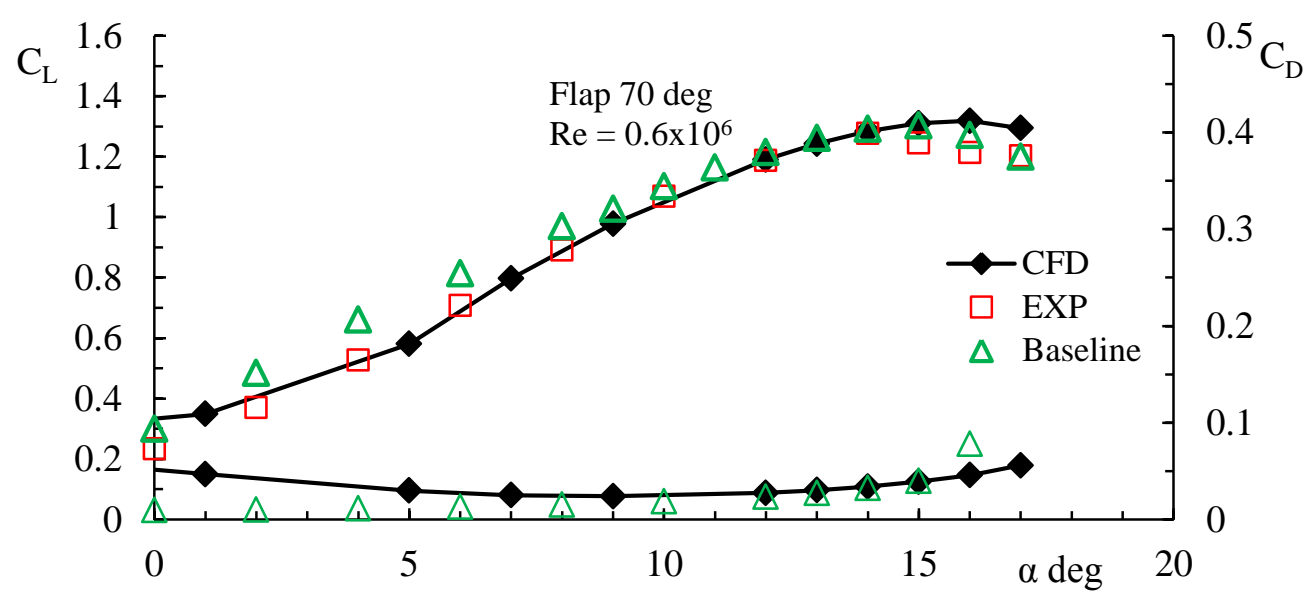

Figure 10: $C_{L}$ and $C_{D}$ plots for $R e=0.6 \times 10^{6}$ over a range of angles of attack of the numerical and experimental results for an aerofoil and flap configuration with $\delta=70^{\circ}$ and a baseline Clark $Y$.

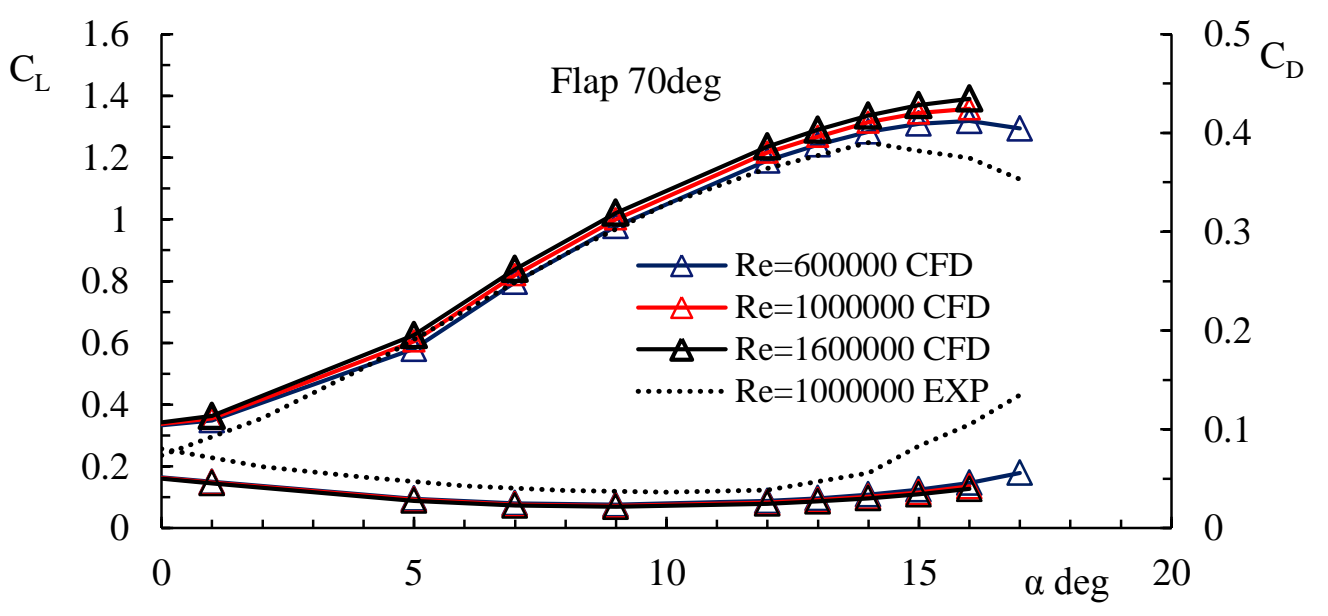

Figure 11: $C_{L}$ and $C_{D}$ plots over a range of Re numbers and angles of attack of the numerical and experimental results for an aerofoil and flap configuration with $\delta=70^{\circ}$.

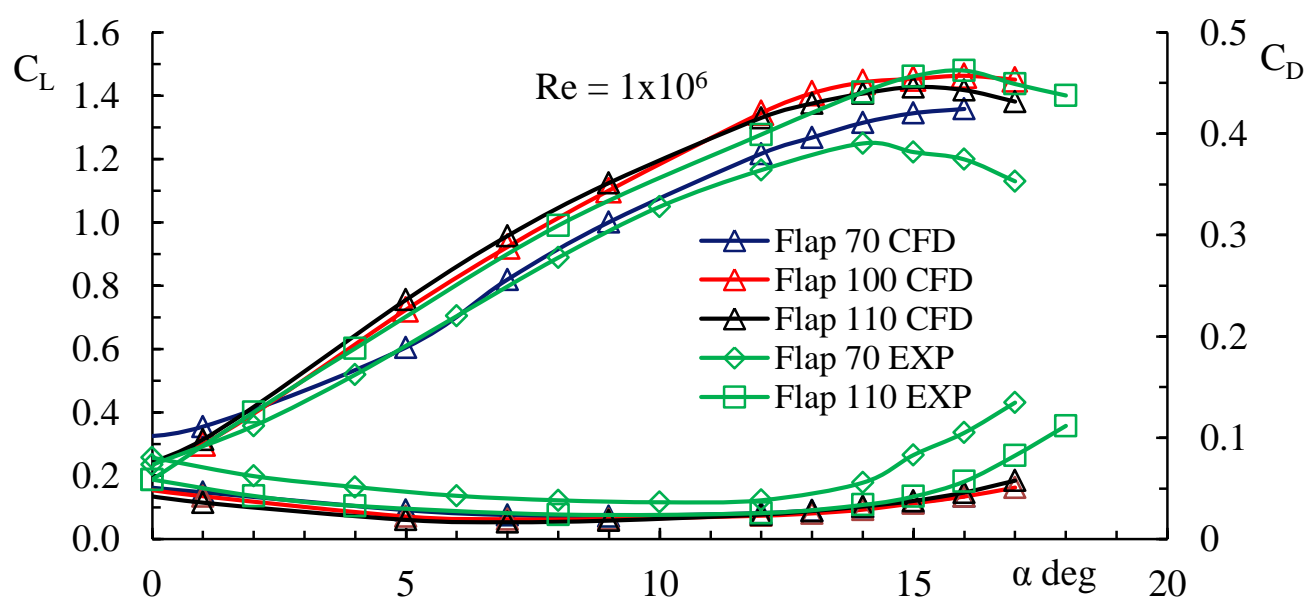

Figure 12: $C_{L}$ and $C_{D}$ plots for $R e=1 \times 10^{6}$ over a range of angles of attack of the numerical and experimental results for an aerofoil and flap configuration with $\delta=70,100,110$. 


\section{Discussion}

The introduction of a flap results in an increase in the lift produced by the aerofoil at high angles of attack $\alpha$. At low flap deflection angle $\delta$ and low $\alpha$, a discontinuity of the flow occurs at the lower surface of the aerofoil thus reducing the total lift produced by the configuration and increasing its drag (see Figure 13 and Figure 14). As $\alpha$ and/or $\delta$ increase, the approaching flow becomes aligned with the flap and an increase in $\mathrm{C}_{\mathrm{L}}$ occurs, with a slight decrease in $C_{D}$ (see Figure 12). Furthermore, it can be seen that the separation zone is around $25 \%$ of the baseline case when the flap is deployed. This crucial interaction between the main aerofoil and the flap is brought about by their relative positions and creates up to $18 \%$ more lift by modifying the airflow around the main aerofoil element. The flap also serves to effectively increase the camber of the aerofoil leading to an increase in its $\mathrm{C}_{\mathrm{L}}$ characteristics.

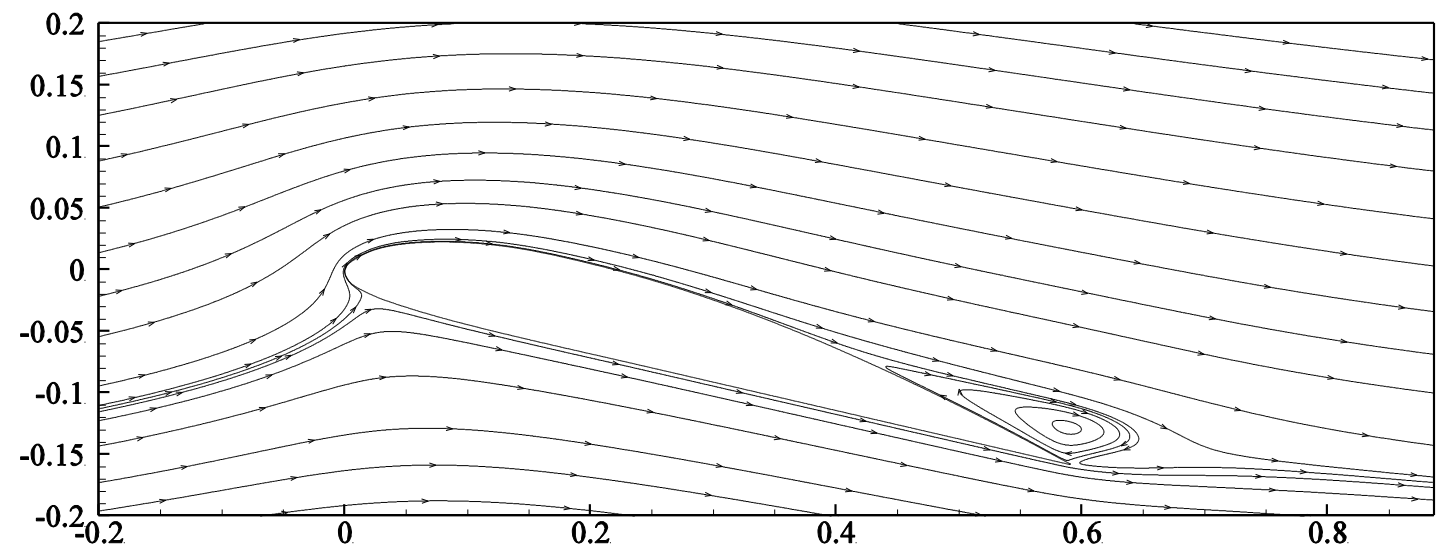

Figure 13: Instantaneous streamlines of Clark $-Y$ aerofoil (baseline) at $\alpha=15^{\circ}$ and $\operatorname{Re}=0.6 \times 10^{6}$.

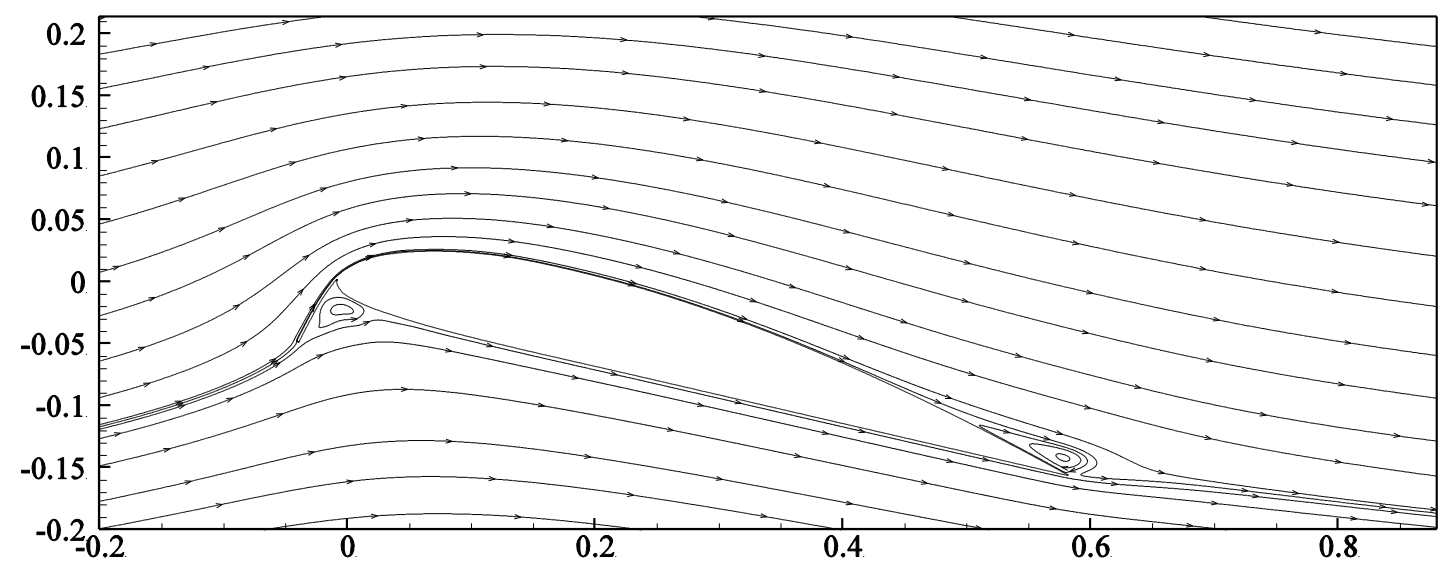

Figure 14: Instantaneous streamlines of aerofoil and flap configuration at $\alpha=15^{\circ}, \delta=100^{\circ}$ and $\operatorname{Re}=0.6 \times 10^{6}$

Consideration of L/D for the CFD data shows an increasing trend between $0<\alpha<12$ for $\delta=70^{\circ}$ and $\delta=100^{\circ}$ reaching a maximum L/D of 50 and 58 respectively at $\alpha=12^{\circ}$, with a progressive decrease in magnitude thereafter. A similar trend is observed for $\delta=110^{\circ}$ reaching a maximum L/D of 61.5 at $\alpha=9^{\circ}$. 


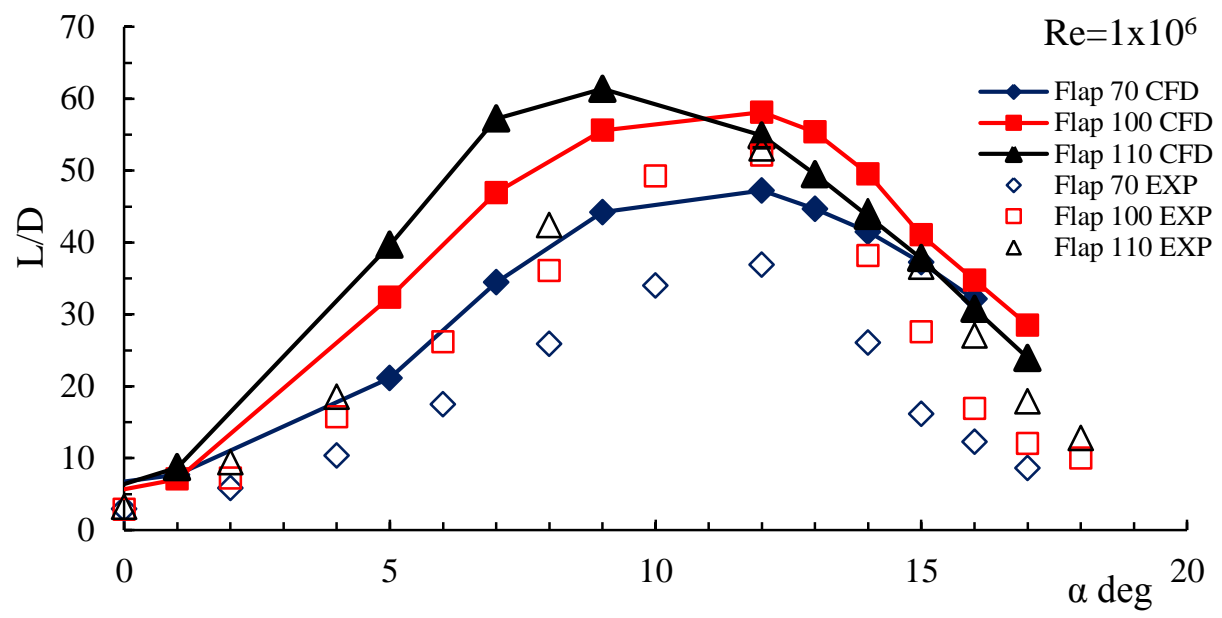

Figure 15: $\mathrm{L} / \mathrm{D}$ plots for $\mathrm{Re}=1 \times 10^{6}$ over a range of flap angle and angles of attack

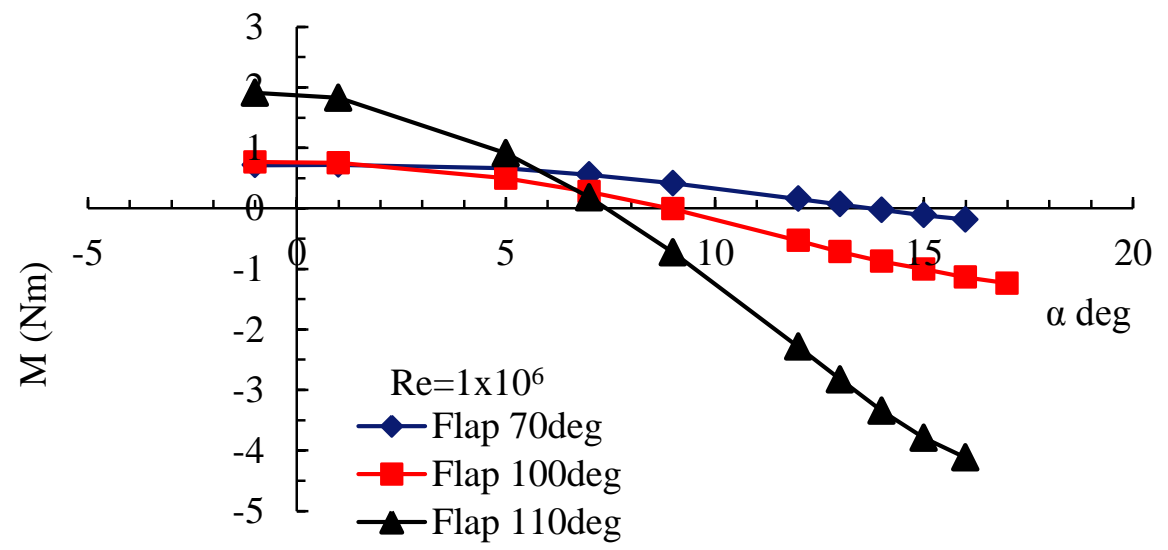

Figure 16: Moment $(M)$ plots for $\operatorname{Re}=1 \times 10^{6}$ over a range of Flap angle and angles of attack

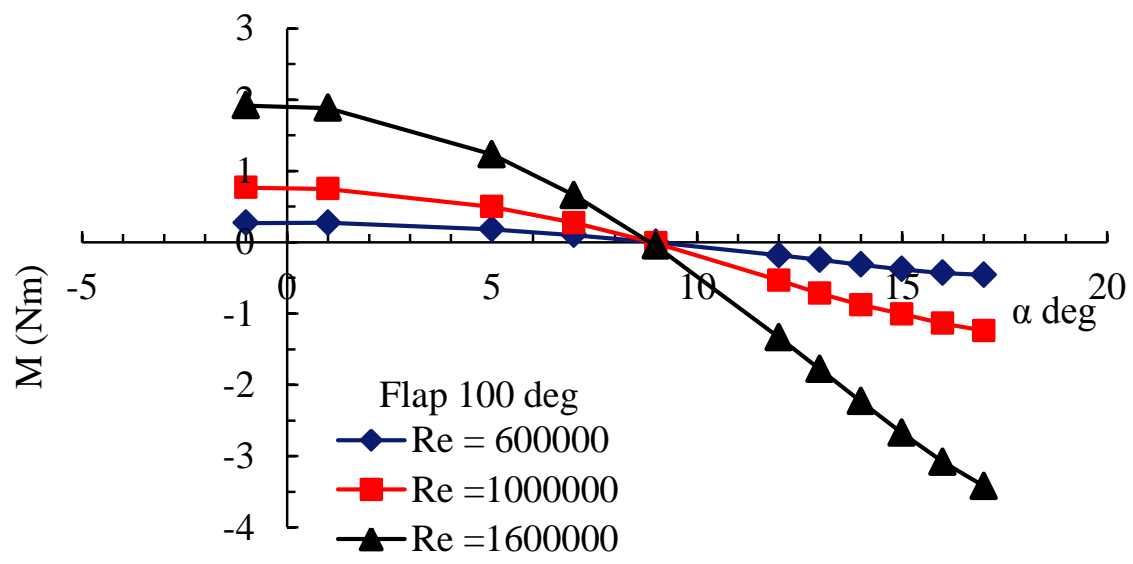

Figure 17: Moment (M) over a range of Re numbers for $\delta=100$ 


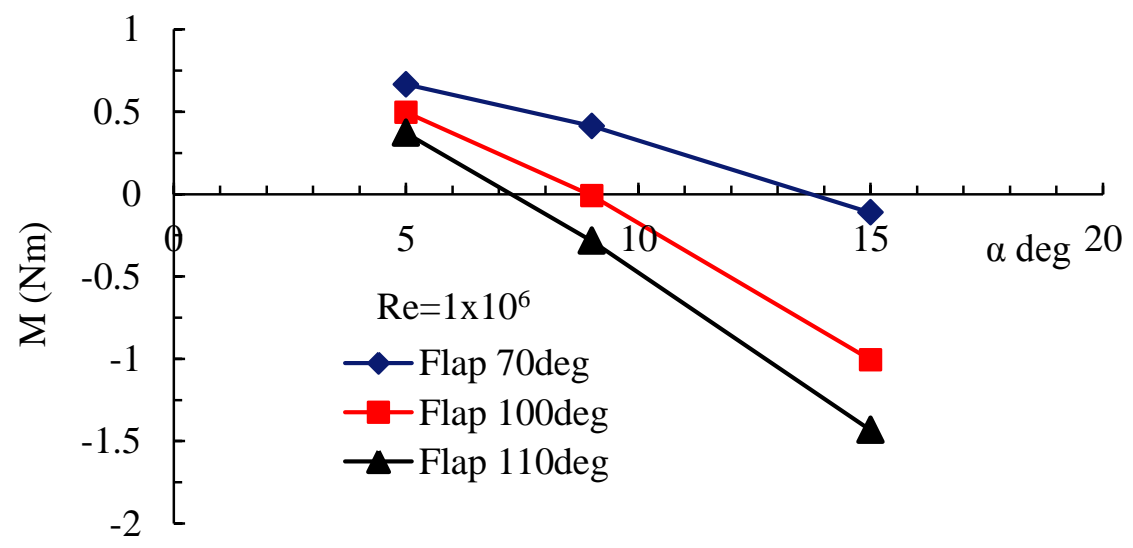

Figure 18: Moment (M) for $\delta=70,100$ and 110 for Re number $1 \times 10^{6}$ and fixed $\alpha$

The increment in $C_{L}$ due to the introduction of the flap was predicted to within $5 \%$ by the CFD for the range of $\alpha$. These CFD results are also consistent with the trend identified from the wind-tunnel data, (see Figure 15). The values of $\mathrm{L} / \mathrm{D}$ ratio however, have differences of up to $35 \%$ between the experimental and numerical data. These differences can be attributed to a) turbulence models which may under predict the values for $\mathrm{C}_{\mathrm{D}}{ }^{(22,23)}$ and $\mathrm{b}$ ) even with the presence of end-plates in the experiment the flow may not be truly two dimensional at the higher flap angles and angles of attack ${ }^{(23,24)}$. Pelletier ${ }^{(24)}$ showed that the presence of endplates for two dimensional aerodynamic testing could lead to errors in $C_{D}$. It was stated that this increase was caused by presence of a corner flow and the boundary layers growing on the end plates. Additionally the effect of the aluminium blocks which connected the flap with the end plates was not calculated.

The moments around the Kruger flap rotation point were also calculated from the numerical analysis as an initial stage in the design of a passive flap system. These moments are illustrated in Figure 16 and Figure 17. It can be seen that the change in moment $(\Delta \mathrm{M})$ with increasing $\alpha$ is negative in all cases whereas the magnitude of the gradient $\Delta \mathrm{M} / \alpha$ increases with increasing $\delta$. Given a moment still exists at zero lift conditions, in a number of $\alpha$ points, the moment is zero. Figure 18 shows a further plot of $\mathrm{M}$ vs $\delta$ for a series of $\alpha$. Given this pseudo-linear relationship, in principle it would be possible to design a simple passive flap deployment system based on a conventional speed loaded pulley and lever arrangement, providing the angle of attack could be used to baseline load the spring. Further design work is needed to confirm this proposal.

\section{Conclusions}

A numerical analysis was performed in parallel with experimental wind tunnel measurements from a Clark Y aerofoil with a $10 \%$ chord, leading edge Kruger flap. The analysis aimed to identify the forces and moments acting on the flap and its aerodynamic performance at Reynolds numbers of $0.6 \times 10^{6}, 1 \times 10^{6}$ and $1.6 \times 10^{6}$, where small and medium size tactical UAVs operate.

A 2D CFD model, validated through experimental data, was used to examine the major flow features around the different Kruger flap angles. CFD lift coefficient results had deviations of less than $5 \%$ in $C_{L}$ value when compared to experimental data.

Previous studies have indicated a Kruger leading edge flap system may be able to offer lift coefficient advantages when used as a self deploying high lift device on a UAV scale aircraft. In this case the CFD and experimental results have shown promising Kruger characteristics with $\mathrm{C}_{\mathrm{L}}$ increases of up to $18 \%$ over the baseline configuration and delayed separation by up to $3^{\circ}$ in angle of attack. Furthermore, the aerofoil and Kruger leading edge flap configuration can maintain a more elevated lift curve over high angles of attack and lower Reynolds numbers. At lower angles of attack, however, the flap does not perform as well. As the flap deployment angle increases, the angle of attack at which the flap becomes effective decreases. 
In the case of application of a Kruger flap on a UAV, such a high lift system offers the potential for a design where the flap deploys automatically during landing, take off and manoeuvring at any given angle of attack. Initial consideration of the moments on the flap itself have shown these characteristics lend themselves to a simple spring based deployment device, providing the angle of attack can be input into the spring control device. Successful application of such devices could potentially provide a less complex leading edge device and increased performance characteristics for a UAV, during takeoff and/or landing. Further work is needed to confirm such design. 


\section{References}

1 Kruger W., Systematic wind tunnel measurements on a laminar aerofoil with nose flap. M.A.P Volkenrode Ref: MAP - VG 123 - 224T, 1946.

2 Jones, A.R., Bakhtian, N. and Babinsky, H. Low Reynolds Number Aerodynamics of Leading Edge Flaps, J. Aircraft, January-February 2008, 45, (1), pp. 342-345

3 Kruger W., The nose flap as a means for increasing the maximum lift of high-speed aeroplanes. M.A.P Volkenrode Ref: MAP - VG 87 - 25T, 1946.

4 Kruger W., Systematic wind-tunnel measurements on a laminar wing with nose flap, NACA-TM-1119, 1947.

5 Fullmer Felicien F., Two-dimensional wind-tunnel investigation of the NACA 641-012 airfoil equipped with two types of leading-edge flap. NACA-TN-1277, 1947.

6 Fullmer Felicien F., Two-dimensional wind-tunnel investigation of an NACA 64 -009 airfoil equipped with two types of leading-edge flap. NACA-TN-1624, 1947.

7 Williams A.L., A new and less complex alternative to the Handley Page slat (Northrop Corp., Aircraft Div., Hawthorne, CA J. Aircraft $19860021-8669$ vol.23 no.3 (200-206).

8 Alexander N., and Shepshelovich M. "Development of High-Lift UAV Wings" 24 ${ }^{\text {th }}$ Applied Aerodynamics Conference 5 - 8 June 2006, San Francisco, California

9 Wilcox D.C., Turbulence Modelling for CFD, Second Edition, DWC Industries Inc. La. Canada, California, ISBN 1-928729-10-X.

10 Spalart, P.R., Trends in Turbulence Treatments, AIAA Paper 2000-2306, June 2000.

11 Menter, F.R., Two-equation eddy-viscosity models for engineering applications, AAIA J. Volume 32, pp. 1598-1605, 1994.

12 Spalart P.R. and Allmaras S.R., A One - Equation Turbulence Transport Model for Aerodynamic Flows, AIAA-92-0439, 30 ${ }^{\text {th }}$ Aerospace Science Meeting \& Exhibit Reno, January 6-9, 1992.

13 Wilcox, D.C., Multiscale Model for Turbulent Flows, AIAA Journal, Vol. 26 No 11. November 1988, pp. 1311-1320.

14 Menter, F. R., Influence of Freestream Values on k- $\omega$ Turbulence Model Predictions, AIAA Journal, Vol. 30, No 6, June 1992, pp. 1657-1659.

15 Pietro Catalano and Marcello Amato, An evaluation of RANS turbulence modelling for aerodynamic applications, Aerospace Science and Technology 7, pp. 493-509, 2003.

16 Tuncer Cebeci, Analysis of Turbulent Flows, Second Revised and Expanded Edition, ISBN 0080443500.

17 Spalart, P.R., Trends in Turbulence Treatments AIAA Paper 2000-2306, June 2000

18 Patrick J. Roache, Verification and Validation in Computational Science and Engineering, Hermosa, 1998 , ISBN 0-913478-08-3.

19 H. K. Versteeg \& W. Malalasekera, An Introduction To Computational Fluid Dynamics, The Finite Volume Method, Prentice Hall, 1995, ISBN 0-582-21884-5. 
Abe Silverstein, Scale effect on Clark Y airfoil characteristics from N.A.C.A. full scale wind-tunnel tests. N.A.C.A report no 502, 1935.

21 A. Shelton, J. Abras, R. Jurenko and M. Smith, Improving the CFD Predictions of Airfoils in Stall, AIAA2005-1227, 43rd AIAA Aerospace Sciences Meeting and Exhibit, Reno, Nevada, Jan. 10-13, 2005.

22 Fred E. Weick and Joseph A. Shortal, The effect of multiple fixed slots and trailing edge flap on the lift and drag of a Clark Y airfoil. N.A.C.A report no 427.

23 Render P.M., Aerofoil measurements at low Reynolds numbers, Cranfield University Report No 8508, 1985

24 Pelletier A. and Mueller T.J., Effect of Endplates on Two- Dimensional Airfoil Testing at Low Reynolds Numbers, J. Aircraft, 38, (6), November - December 2001 